\title{
REPAIR DURABILITY OF A WATER-AGED MICROFINE HYBRID RESTORATIVE RESIN COMPOSITE: A NANO-LEAKAGE STUDY
}

\author{
Marwa A. El-Tahtawi*, Ahmed A. Laithy **, \\ Zainab M. Diaa El-Din Soliman** and Farid S. El-Askary***
}

\begin{abstract}
Aim: To evaluate the effect of using two types of flowable resin composites and storage time on nano-leakage of repaired water aged resin composite.
\end{abstract}

Materials and Methods: In total, 30 resin composite discs were prepared and stored in distilled water for $6 \mathrm{~m}$. The discs were then randomly divided into 6 experimental groups ( $\mathrm{n}=5 /$ group) according to the two experimental factors of the study: Factor 1: Flowable composite, 3 groups (no-flowable, high-viscosity and low-viscosity flowable composites), and Factor 2; Storage time after repair, 2 groups ( $24 \mathrm{~h}$ and $6 \mathrm{~m}$ ). Repair procedures were carried out using universal adhesive with and without the application of the flowable composite. After repair, half of the specimens were stored for $24 \mathrm{~h}$ and the other half were stored for $6 \mathrm{~m}$ in distilled water. After the recommended storage time, each disc was sectioned into 2 halves and each half was prepared for silver nitrate staining procedures to evaluate the nano-leakage under SEM. Three photomicrographs were taken for each half-slab, resulting in 30 photomicrographs/group, which were analyzed using ImageJ software. Data were evaluated using Kruskal-Wallis/Mann-Whitney test $(P=0.05)$.

Results: The use of flowable composite had no significant effect on nano-leakage $(P=0.129)$, while storage time showed a statistically significant effect on nano-leakage $(P<0.0001)$. There was no statistically significant difference regarding the use of flowable resin composite either at $24 \mathrm{~h}$ or $6 \mathrm{~m}$ storage times $(P>0.05)$. There was a statistically significant difference between $24 \mathrm{~h}$ and $6 \mathrm{~m}$ storage periods for all experimental variables $(P<0.05)$.

Conclusion: The two types of flowable composites were not able to prevent the uptake of silver nitrate at the composite/composite interface either after $24 \mathrm{~h}$ or $6 \mathrm{~m}$.

KEYWORDS: Resin composite, Aging, Flowable composite, Durability, Nano-leakage.

\footnotetext{
* Master Degree Student, Operative Dentistry Department, Faculty of Dentistry, Ain Shams University. ** Lecturer, Operative Dentistry Department, Faculty of Dentistry, Ain Shams University.

*** Professor, Operative Dentistry Department, Faculty of Dentistry, Ain Shams University.
} 


\section{INTRODUCTION}

Resin-based composites are resinous materials that consisted of two main components, the organic resin matrix, in which inorganic fillers are embedded. The two main components are coupled with each other by silane coupling agent. ${ }^{(1,2)}$ The decrease in $\mathrm{C}=\mathrm{C}$ double bond, ${ }^{(3,4)}$ the increase in water sorption, hydrolytic degradation, and release of the free monomers, ${ }^{(5,6)}$ could be the consequences of the aging process of resin composite.

Repair is considered a "minimally invasive approach", ${ }^{(7)}$ that encourages some clinicians to prefer it over the total replacement of the failed restorations. During clinical service, resin composites could suffer from some clinical failures, such as fracture, recurrent caries, tooth structure fracture, or aesthetic problems. ${ }^{(8)}$ Among the main reasons that cause clinicians to prefer repair of the above mentioned failures over total replacement are the risk of pulp involvement and the excessive removal of sound tooth structure ${ }^{(9)}$ Elimination of additional preparation of sound tooth structure for placing mechanical retention, ${ }^{(7)}$ lower cost of the restorative treatment, as well as, shorter restorative procedures duration are other additional factors for repair preference. ${ }^{(9)}$

Universal adhesives are mainly self-etching adhesives and are the most simplified form of marketed adhesives. They are present in single bottles, and according to their manufacturers they can be applied in etch-and-rinse, self-etching or selective-enamel etching modes. ${ }^{(10)}$ The use of universal adhesives to improve repair quality of aged different resin composites was evaluated in previous studies, ${ }^{(11-14)}$ with their durability was reported to be questionable. ${ }^{(12-14)}$ An extra-hydrophobic adhesive layer was used in an attempt to improve the durability of the different universal adhesives. ${ }^{(10)}$ The use of a layer of flowable resin composite was another approach to increase the durability of composite/composite bond.(14) The application of flowable composites over cured adhesive layer and its effect on composite-composite interface quality did not gain much attention in the previous studies.

The quality of composite-to-composite bond could be assessed using different assessment laboratory methods. According to previous studies, the two most commonly used laboratory methods were the bond strength and the examination of fractured surface using stereo- or Scanning Electron Microscopes. ${ }^{(15-17)}$ Nano-leakage is another way to evaluate the quality of the repair interface, which depends on tracing of silver nitrate particles along the composite-composite interface. ${ }^{(12-14)}$ The advantage of nano-leakage methodology was that this method could be able to detect even the early signs of poor composite-composite interface quality, yet the repair bond strength was not affected. ${ }^{(13)}$

Therefore, the aim of this study was to evaluate the effect of the application of an extra-layer of flowable composites with different viscosities and storage time on repair quality of water-aged microfine hybrid resin composite. The null hypothesis tested was that neither the application of the flowable composite, nor the storage time influenced the repair quality of the water-aged micro-fine hybrid resin composite.

\section{MATERIALS AND METHODS}

One restorative micro-fine hybrid resin composite and two flowable resin composites were used in this study. Materials (Descriptions), composition, manufacturers and Lot \# are listed in Table 1.

\section{Sample grouping}

A total of 30-resin composite discs (shade A2) were divided into 6 experimental groups $(n=5 /$ group) according to the two experimental factors in this study: Factor 1, Flowable resin composite application, 3 groups (no-flowable, high-viscosity flowable and low-viscosity flowable resin composites) and Factor 2, Storage time after repair, 2 groups ( $24 \mathrm{~h}$ and $6 \mathrm{~m}$ ). 
TABLE (1) Materials (Description), Composition, Manufacturers and Lot \#.

\begin{tabular}{|c|c|c|c|}
\hline Materials (Descriptions) & Composition & Manufacturers & Lot \# \\
\hline $\begin{array}{l}\text { GC Gradia }{ }^{\circledR} \text { Direct Anterior } \\
\text { (Micro-fine hybrid resin } \\
\text { composite) }\end{array}$ & $\begin{array}{l}\text { Fillers: Silica ( } 22 \text { vol \%), pre-polymerized filler }(0.85 \mu \mathrm{m} \text {, } \\
42 \text { vol. } \%) \text {. } \\
\text { Organic matrix: UDMA and di-methacrylate co-monomers. } \\
\text { Pigments, catalysts. }{ }^{(18)}\end{array}$ & $\begin{array}{l}\text { GC Dental } \\
\text { Products Corp., } \\
\text { Tokyo, Japan. }\end{array}$ & $\begin{array}{l}\text { Shade A2 } \\
1612162 \\
\text { Shade A3.5 } \\
1602152\end{array}$ \\
\hline $\begin{array}{l}\text { G-aenial Universal Flo } \\
\text { (High-viscosity flowable nano- } \\
\text { hybrid resin composite, shade } \\
\text { A2) }\end{array}$ & $\begin{array}{l}\text { Resin matrix: UDMA, Bis-MEPP, TEGDMA. } \\
\text { Filler content: Silicon dioxide (16 nm), strontium glass } \\
(200 \mathrm{~nm}) .^{(19)}\end{array}$ & $\begin{array}{c}\text { GC Dental } \\
\text { Products Corp. }\end{array}$ & 1608172 \\
\hline $\begin{array}{l}\text { G-aenial Flo } X \\
\text { (Low-viscosity flowable nano- } \\
\text { hybrid resin composite, shade } \\
\text { A2) }\end{array}$ & $\begin{array}{l}\text { Resin matrix: Bis-MEPP, a modification of Bis-GMA, } \\
\text { compatible with UDMA and Bis-GMA. } \\
\text { Filler loading: ( } 46 \text { vol. } \%, 69 \text { wt. } \% \text { ) particle size } \\
\text { 700nm. }{ }^{(20)}\end{array}$ & $\begin{array}{c}\text { GC Dental } \\
\text { Products Corp. }\end{array}$ & 1605092 \\
\hline G-Premio Bond & $\begin{array}{l}\text { 10-MDP }(5-10 \%), 4-M E T, \text { dimethacrylate }(10-20 \%) \text {, } \\
\text { dimethacrylate component }(1-5 \%) \text {, photo-initiator }(1-5 \%) \text {, } \\
\text { butylated hydroxytoluene }(<1 \%) \text {, acetone }(25-50 \%) \text {, water } \\
(24 \%){ }^{(21)}\end{array}$ & $\begin{array}{c}\text { GC Dental } \\
\text { Products Corp. }\end{array}$ & 1707182 \\
\hline \multicolumn{4}{|c|}{$\begin{array}{l}\text { 4-MET, 4-methacryloyloxyethyl trimellitate; 10-MDP, 10-methacryloyloxydecyl di-hydrogen phosphate; TEGDMA, } \\
\text { triethylene glycol dimethacrylate.; Bis-MEPP 2,20-Bis-4-methacryloylethoxyphenyl propane; UDMA, Urethane } \\
\text { Dimethacrylate. }\end{array}$} \\
\hline
\end{tabular}

\section{Samples preparation}

All resin composite discs were prepared using split Teflon molds. Each mold had a central hole of 8 $\mathrm{mm}$ in diameter and $3 \mathrm{~mm}$ in depth and its two halves were assembled using a copper ring. Each mold was placed over a piece of transparent polyacetate sheet rested over a glass slab. The resin composite (Shade A2) was applied inside the mold's hole in two increments, each was approximately $1.5 \mathrm{~mm}$ in thickness, and light cured using LED light curing unit (Ledition, Ivoclar Vivadent, Germany) for 20s each according to the manufacturer's instructions. The LED light curing unit output was $600 \mathrm{~mW} / \mathrm{cm} 2$. A transparent polyacetate sheet was applied to cover the surface of the resin composite before light curing of the second composite increment, and covered with a glass slide, then gently pressed to create a flat surface and to extrude excess materials. The molds were disassembled, the discs were removed from the mold and were stored in distilled water at room temperature for $6 \mathrm{~m}$ before repair. Distilled water was changed weekly throughout the whole storage period.

\section{Repair of aged resin composite}

After the $6 \mathrm{~m}$ storage time, the discs were ground using high-speed yellow coded abrasive burs (PD05HPTC NO. 1509, TR-13EF, Taiwan) mounted on a high-speed handpiece (W\&H, RC-90, Austria) with copious air/water spray. Each disc received five grinding strokes applied in one direction. One abrasive bur was used per each group. The ground surfaces were air dried using oil-free compressed air. A universal adhesive was applied over all aged disc surfaces and gently rubbed using a micro-brush for $10 \mathrm{~s}$ according to the manufacturer instructions. The adhesive was air dried for $5 \mathrm{~s}$ under maximum pressure and light cured for $10 \mathrm{~s}$ using the LED light curing unit. After that, each disc was inserted inside another split Teflon mold with a central hole 
of $8 \mathrm{~mm}$ in diameter x $6 \mathrm{~mm}$ in depth. Shade A3.5 resin composite was packed over the cured adhesive in two separate increments of approximately 1.5 $\mathrm{mm}$ thickness each. The first increment was light cured for $20 \mathrm{~s}$. Before light curing of the second increment, a piece of polyacetate sheet was applied on its top and a glass slide was positioned over the polyacetate sheet. The material was gently pressed and was light cured for $20 \mathrm{~s}$. After light curing, the discs were removed from the molds, half of the discs were stored in distilled water for $24 \mathrm{~h}$ and the other half was stored in distilled water for $6 \mathrm{~m}$ (the no-flowable group). During the $6 \mathrm{~m}$ storage period distilled water was changed weekly.

For the flowable composite groups, after light curing of the adhesive, each disc was weighted using a digital balance (ST, model Bs 150, Taiwan). The flowable composite was injected in the center of each disc in a ball-shaped increment. Each disc with its overlaying flowable composite was then reweighted using the same balance to standardize the amount of the applied flowable resin composite. ${ }^{(22)}$ The average weight of low-viscosity flowable resin composite was $0.0125 \pm 0.0026$ gram, and the average weight of high-viscosity flowable composite was $0.013 \pm 0.0026$ gram. The flowable composite was spread over the disc using double flat metallic instrument. The spread of the flowable composite was performed to standardize as much as possible a uniform flowable composite layer thickness. The flowable composite was light cured for $20 \mathrm{~s}$ according to the manufacturer instructions. Each disc was placed in another split Teflon mold with a circular hole of $8 \mathrm{~mm}$ in diameter and 6 $\mathrm{mm}$ in depth and shade A3.5 resin composite was applied, and light cured as described for the noflowable groups. The repaired composite discs were stored as same for the no-flowable groups.

\section{Preparation of half-discs for nano-leakage evaluation}

After the recommended storage time, the discs were removed from the distilled water, and was sectioned into two halves using abrasive coated discs mounted on a low speed straight hand piece (NSK, EX-6, Japan) under copious water irrigation. Each abrasive disc was used for five resin composite discs. The flat surface of each half-disc was wet polished using ascending grits of $\mathrm{SiC}$ papers (\#600, $\# 800$, \#1000, and \#1200 respectively), each for 1 minute. The half-discs were air dried, and each halfdisc was covered with 2 coats of nail varnish leaving $1 \mathrm{~mm}$ from both sides of the composite-composite interface.

\section{Preparation of silver nitrate solution}

An ammoniacal silver nitrate solution was prepared according to the method described by Pashley, et al. ${ }^{(23)}$ The prepared half-discs were immersed in the silver nitrate solution and were left in the solution for $24 \mathrm{~h}$ in light proof containers. After $24 \mathrm{~h}$, the half-discs were removed and washed under running water for $5 \mathrm{~min}$. The halfdiscs were immersed in developing solution for 8 $\mathrm{h}$ under fluorescent light. After the recommended immersion time, each half-disc was air dried and the nail varnish was scraped using a surgical blade. The flat surface of each half-disc was polished using ascending grits of SiC papers (\#1000,\#1200), and finally using resin composite polishing past (Diamond polish $0.5 \mu \mathrm{m}$, Ultradent Products Inc., USA) over a polishing cloth.

\section{SEM evaluation of nano-leakage}

Each half-disc was sputtered with gold (EMITECH K550X sputter coater, England) and evaluated using the SEM (SEM Model Quanta 250 FEG, FEI Company, Netherlands) in a backscattered mode with accelerating voltage of $30 \mathrm{~K} . \mathrm{V}$. The entire interface was scanned at magnification $200 \mathrm{x}$ for quantitative analysis. Selected areas of the nano-leakage within each half-disc were scanned at higher magnifications for qualitative analysis. Each half-disc was scanned, and a photo was captured in the middle of the half-disc. Two additional photos were captured one from the right of the first photo and the other was captured from the left of the first 
one. Three photomicrographs were taken from each disc. Each photo was analyzed using the ImageJ/ Fiji 1.51j8 software [Wayne Rasband, National institutes of health, USA, http://imagej.nih.gov/ ij, Java 1.8.0_112 (64-bit), 4212K of 2921MB $(<1 \%)]$. Each photo was opened inside the program and the scale was set by measuring the line of the scale bar of each photo. A line was drawn to record the full length of the interface. Another line was drawn to record the length of the nano-leakage at the composite/composite interface. Separate nanoleakage areas were measured using separate lines and the total length of the nano-leakage at the interface was calculated by the sum of all separate measuring lines.

The nano-leakage percentage for each photo was calculated according to the following equation:

$\frac{\text { The length of nano-leakage }}{\text { The total length of the interface }} \times 100$

The percentage of the nano-leakage of the three photos of each half-disc was averaged and the mean percentage of nano-leakage/group was calculated from the 10 half-discs.

The nano-leakage percentage of all SEM photomicrographs per each experimental group was scored according to Saboia, et al. ${ }^{(24)}$ into to the following Scores: Score 0: 0\%, Score 1: $>0 \%$ - $\leq 25 \%$, Score 2: $>25 \%$ - $\leq 50 \%$, Score 3: $>50 \%$ $\leq 75 \%$, and Score $4:>75 \%-100 \%$.

The silver nitrate uptake sites at the repair interface of all SEM photomicrographs per each experimental group were assessed and categorized according to the following categories: Category 0: No nano-leakage, Category 1: Nano-leakage occurred between adhesive and aged resin composite, Category 2: Nano-leakage occurred between adhesive and repair resin composite, Category 3: Nano-leakage occurred within the adhesive layer, Category 4: Nano-leakage occurred between adhesive and flowable resin composite, and Category 5: Nano-leakage occurred between flowable resin composite and repair composite.

\section{Statistical analysis}

Statistical analysis was performed using SPSS statistical analysis program for Window's (Version 21). Kruskal-Wallis Test was performed to test the effect of the use of flowable resin composite and storage time on nano-leakage percentage. MannWhitney Test was used to evaluate the effect of the use of flowable resin composite within each storage time and the effect of storage time within each flowable resin composite. Significant level was set as $P=0.05$.

\section{RESULTS}

The use of flowable resin composite had no significant effect on the degree of nano-leakage $(P=0.129)$. On the other hand, storage time showed a statistically significant effect on the degree of the nano-leakage $(P<0.0001)$. Table 2 revealed that there was no statistically significant difference between no-flowable, high-viscosity flowable and low-viscosity flowable either at $24 \mathrm{~h}$ or $6 \mathrm{~m}$ storage times $(P>0.05)$. There was a statistically significant difference between the $24 \mathrm{~h}$ and the $6 \mathrm{~m}$ storage times for the no-flowable, the high-viscosity and the low-viscosity flowable resin composites $(P<0.0001$, $P=0.022$ and $P<0.0001$ respectively).

TABLE (2) Means \pm standard deviation (median) of the nano-leakage percentage within each experimental variable.

\begin{tabular}{|c|c|c|c|}
\hline & $\mathbf{2 4 ~ h}$ & $\mathbf{6 ~ m}$ & P Value \\
\hline No-flowable & $\begin{array}{c}28.7 \pm 18.4^{\mathrm{a}} \\
(22.1)\end{array}$ & $\begin{array}{c}65.1 \pm 30.4^{\mathrm{b}} \\
(69.6)\end{array}$ & $<0.0001$ \\
\hline $\begin{array}{c}\text { High-viscosity } \\
\text { flowable }\end{array}$ & $\begin{array}{c}32.5 \pm 25.7^{\mathrm{a}} \\
(29.7)\end{array}$ & $\begin{array}{c}53.6 \pm 36.1^{\mathrm{b}} \\
(55.3)\end{array}$ & 0.022 \\
\hline $\begin{array}{c}\text { Low-viscosity } \\
\text { flowable }\end{array}$ & $\begin{array}{c}39.7 \pm 23.6^{\mathrm{a}} \\
(27.6)\end{array}$ & $\begin{array}{c}69.5 \pm 29.3^{\mathrm{b}} \\
(79.8)\end{array}$ & $<0.0001$ \\
\hline
\end{tabular}

Mean with same small superscript letters within each column are not statistically significant at $P=0.05$.

$P$ value: Mann-Whitney test for the effect of storage time within each material at $P=0.05$ 


\section{Nano-leakage Score}

Scores 1 and 4 represented the highest percentage (24.44\% and $24.44 \%$ respectively), followed by Score 3 (22.78 \%), Score 2 (21.67\%). Score 0 represented the lowest nano-leakage Score (6.67 \%). The distribution of nano-leakage Score percentages within each experimental variable are summarized in Table 3.

\section{Categorization of nano-leakage sites}

One hundred and eighty photos ( $\mathrm{n}=30 /$ group) were categorized according to the nano-leakage site. The percentage of nano-leakage sites within each group are presented in Table 4. Category 3 showed the highest percentage in all experimental groups (63.89\%), followed by Category 1 (25 $\%)$, Category $0(6.67 \%)$, Category $2(3.89 \%)$ and Category $4(0.56 \%)$. Category 5 showed the lowest nano-leakage percentage $(0.00 \%)$. Representative SEM photomicrographs from each Category are presented in Figures 1 A-G.

TABLE (4) Categorization of nano-leakage percentage between all experimental variables (Number of
TABLE (3) Distribution of Nano-leakage Score percentage (number of photos/total number of photos) within each experimental variable.

\begin{tabular}{|c|ll|}
\hline $\begin{array}{c}\text { Experimental } \\
\text { Variables }\end{array}$ & \multicolumn{2}{|c|}{ Percentage of Nano-leakage within } \\
each Score
\end{tabular}

\section{photos/total number of photos).}

\begin{tabular}{|l|c|c|c|c|c|c|}
\hline & $\begin{array}{c}\text { No-Flowable/ } \\
\mathbf{2 4} \mathbf{h}\end{array}$ & $\begin{array}{c}\text { High- viscosity } \\
\text { Flowable/ 24 h }\end{array}$ & $\begin{array}{c}\text { Low-viscosity } \\
\text { Flowable/ 24 h }\end{array}$ & $\begin{array}{c}\text { No-Flowable/ } \\
\mathbf{6 ~ m}\end{array}$ & $\begin{array}{c}\text { High- viscosity } \\
\text { Flowable/6 m }\end{array}$ & $\begin{array}{c}\text { Low- viscosity } \\
\text { Flowable/6 m }\end{array}$ \\
\hline \multirow{2}{*}{ Category 0 } & $0 \%$ & $16.67 \%$ & $0 \%$ & $6.67 \%$ & $16.67 \%$ & $0 \%$ \\
& $(0 / 30)$ & $(5 / 30)$ & $(0 / 30)$ & $(2 / 30)$ & $(5 / 30)$ & $(0 / 30)$ \\
\hline \multirow{2}{*}{ Category 1 } & $53.33 \%$ & $33.33 \%$ & $40 \%$ & $13.33 \%$ & $6.67 \%$ & $3.33 \%$ \\
& $(16 / 30)$ & $(10 / 30)$ & $(12 / 30)$ & $(4 / 30)$ & $(2 / 30)$ & $(1 / 30)$ \\
\hline \multirow{2}{*}{ Category 2 } & $10 \%$ & $0 \%$ & $0 \%$ & $13.33 \%$ & $0 \%$ & $0 \%$ \\
& $(3 / 30)$ & $(0 / 30)$ & $(0 / 30)$ & $(4 / 30)$ & $(0 / 30)$ & $(0 / 30)$ \\
\hline \multirow{2}{*}{ Category 3 } & $36.67 \%$ & $46.67 \%$ & $60 \%$ & $66.67 \%$ & $76.67 \%$ & $96.67 \%$ \\
& $(11 / 30)$ & $(14 / 30)$ & $(18 / 30)$ & $(20 / 30)$ & $(23 / 30)$ & $(29 / 30)$ \\
\hline \multirow{2}{*}{ Category 4} & $0 \%$ & $3.33 \%$ & $0 \%$ & $0 \%$ & $0 \%$ & $0 \%$ \\
& $(0 / 30)$ & $(1 / 30)$ & $(0 / 30)$ & $(0 / 30)$ & $(0 / 30)$ & $(0 / 30)$ \\
\hline \multirow{2}{*}{ Category 5 } & $0 \%$ & $0 \%$ & $0 \%$ & $0 \%$ & $0 \%$ & $0 \%$ \\
& $(0 / 30)$ & $(0 / 30)$ & $(0 / 30)$ & $(0 / 30)$ & $(0 / 30)$ & $(0 / 30)$ \\
\hline
\end{tabular}



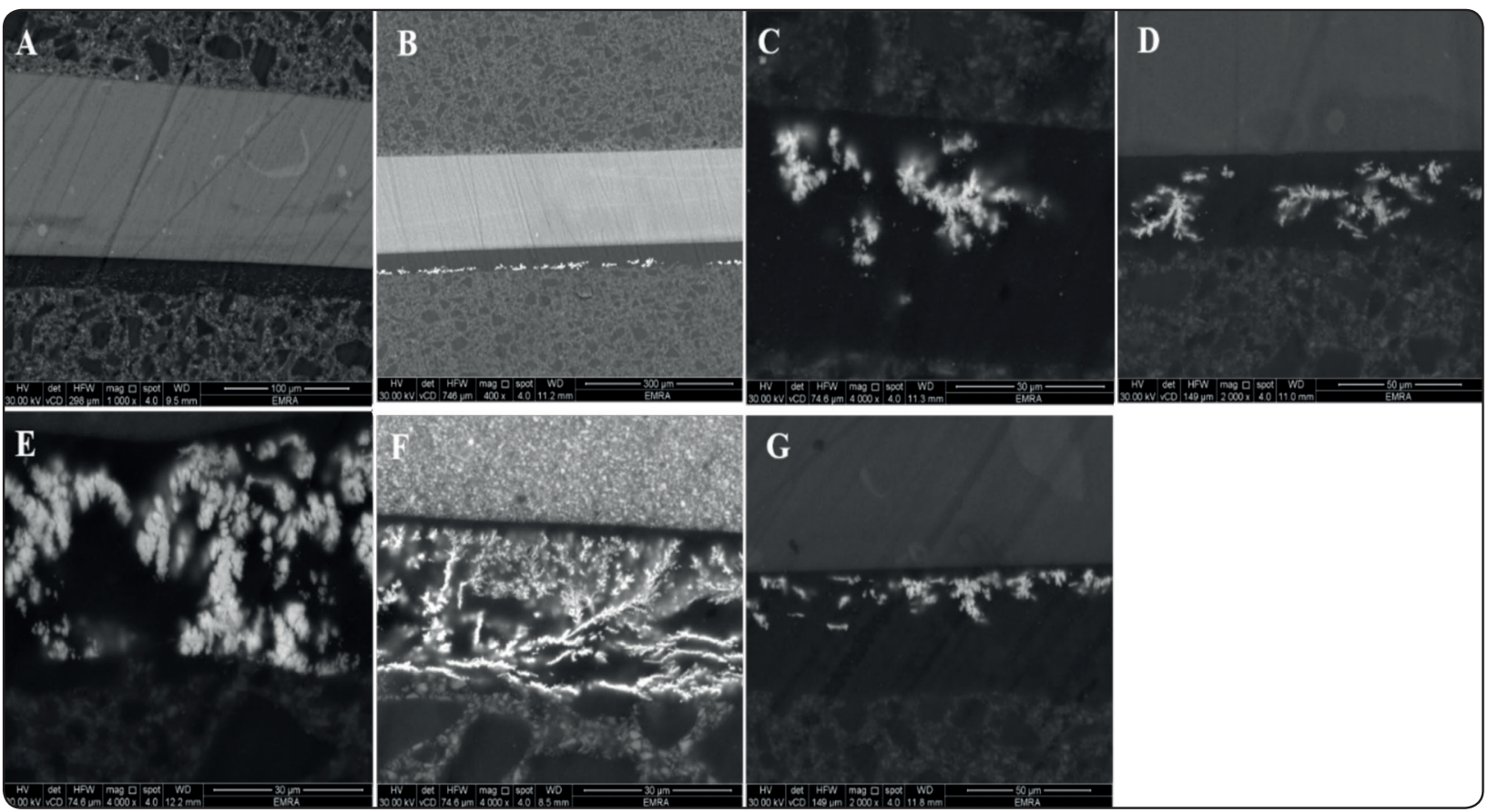

Fig. (1) A-F: A: SEM photomicrographs for Category 0 of high-viscosity flowable composite group after $6 \mathrm{~m}$ of water-storage. No silver nitrate deposition along composite-composite interface was detected (1000x). B: SEM photomicrographs for Category 1 of low-viscosity flowable composite group after $24 \mathrm{~h}$ of water-storage. Silver nitrate depositions were detected at adhesive/aged resin composite interface (400x). C: SEM photomicrographs for Category 2 of no-flowable composite group after $24 \mathrm{~h}$ of water-storage. The presence of separate islands of silver nitrate deposits were detected close to the adhesive/repair composite interface. The silver nitrate deposits showed inverted water-trees pattern (4000x). D: SEM photomicrographs for Category 3 of high-viscosity flowable composite group after $24 \mathrm{~h}$ of water-storage. Silver nitrate depositions were detected within the adhesive layer (2000x). E: SEM photomicrographs for Category 3 of high-viscosity flowable composite group after $24 \mathrm{~h}$ of water-storage. Two nano-leakage patterns within the adhesive layer. The first was water-tree pattern, which located at close proximity to the adhesive/aged composite interface, while the second was the inverted water-tree pattern that occupied the area close to the adhesive/repair composite interface (4000x). F: SEM photomicrograph for category 3 of low-viscosity flowable composite group after $6 \mathrm{~m}$ of water-storage. Severe silver nitrate deposits occupied the full length of the adhesive layer, with multiple water-tree pattern that filled the entire thickness of the adhesive layer (4000x). G: SEM photomicrographs for Category 4 of high-viscosity flowable composite group after $24 \mathrm{~h}$ of water-storage. The presence of silver nitrate deposits was detected close to the adhesive/flowable composite interface, which showed inverted water-tree pattern $(2000 x)$.

\section{DISCUSSION}

Repair as a "minimally invasive approach" involves the removal of the defected part of the existed restoration and restores it by adding a new material that bond to both tooth tissues and old restoration. ${ }^{(25)}$ The application of adhesive in this study was aimed to mimic, as much as possible, what happened in the different clinical situations. Defected restorations, in the most clinical situations, not only involved the restorative material itself, but also involved the tooth tissues, either enamel and/ or dentin. Upon treatment of tooth tissue, adhesive application becomes mandatory step.

Flowable composite material was introduced to overcome the problem of cavity walls adaptation that lacks in the conventional resin composite materials with regular-viscosity.(26) As flowable composite was used as an "intermediate agent" during resin composite repair, the bond strength was reported to be improved with no leakage and better marginal quality. ${ }^{(14)}$ 
There are many microscopic observation methods to evaluate qualitatively and quantitively the nano-leakage, yet each method could lead to its unique nano-leakage pattern. ${ }^{(27)}$ In this study, it seemed that the use of SEM appeared to be an appropriate microscopic observation method to evaluate nanoleakage both qualitatively and quantitively.

The results of this study showed that the type of flowable resin composite did not prevent the nanoleakage at the repair interface (Table 2). The results could be explained by the presence of high percentage of silver nitrate deposits either within the adhesive layer (Category 3) or between the adhesive layer and the aged composite (Category 1). The results showed that Category 3, ranged from $36.67 \%$ up to $60.00 \%$, while Category 1 ranged from $33.33 \%$ to $53.33 \%$ after $24 \mathrm{~h}$, regardless to the flowable resin composite used. As the resin composite was stored for $6 \mathrm{~m}$ before being repaired, water sorption was expected with surface degradation of the resin composite. ${ }^{(28)}$ Water sorption causes "hygroscopic" and "hydrolytic degradation" of dental composites. (29) Surface degradation could increase surface roughness ${ }^{(15)}$ with the entrapment of water within the degradable surface layer. ${ }^{(30)}$ Upon the application of the adhesive, air dryness is able to remove water from the adhesive, but the short air dryness time, $5 \mathrm{~s}$ as recommended by the manufacturer, could not be enough to get rid of water that was entrapped within the surface layer of the aged resin composite.

In the SEM photomicrographs of Category 4 (Figure 1G), the presence of inverted water-tree nano-leakage pattern might be resulted from the evaporation of retained water in the degradable surface layer of the aged composite during light curing of the adhesive. ${ }^{(31)}$ During light curing of the adhesive, the heat generated $^{(31)}$ could cause the evaporation of water from the surface of the resin composite to reach the adhesive layer, which upon setting the water became entrapped within the adhesive layer. During the application of the flowable resin composite the water that evaporated during light curing of the adhesive faced the hydrophobic resin composite, caused its repulsion. This could lead to migration of water away from the hydrophobic flowable resin composite layer. During the immersion of the half-discs in the silver nitrate solution, the silver nitrate particles followed these water channels that entrapped within the adhesive upon its setting, leading to the inverted water-tree pattern.

The same observation was also noticed in some SEM photomicrographs of Category 2 (Figure 1B) and Category 3 (Figure 1E). In Category 3, as the presence of nano-leakage was within the adhesive layer, two distinct nano-leakage patterns were observed. In the first one, the silver nitrate particles followed the water channels that were close to the aged resin composite surface, which could be the cause of inadequate evaporation of water from the adhesive during its air-drying step. The second one was an inverted water-tree pattern, which could be the cause of the repulsion of the evaporated water during the application of the hydrophobic resin composite layer.

The results of this study were partially in agreement with the study of Papacchini et al, ${ }^{(14)}$ regarding the use of adhesive layer over aged composite. They showed that the presence of adhesive layer over aged composite did not prevent the uptake of silver nitrate particles before or after thermocycling. The high nano-leakage was observed within the adhesive layer regardless of its hydrophobicity. On the contrary, they reported that the use of low-viscosity flowable composite revealed no nano-leakage, which disagreed with the results of this study. The difference between the results of this study and the results of Papacchini, et al., ${ }^{(14)}$ regarding the use of flowable composite, could be attributed to the way of the application of the flowable composite. In the study of Papacchini, et al. ${ }^{(14)}$ the flowable composite was applied without the use of the intermediate adhesive layer. In the presence study, flowable composite was applied over the cured adhesive layer, which was a one-step self-etching adhesive. 
For the $6 \mathrm{~m}$ storage period, nano-leakage patterns increased after $6 \mathrm{~m}$ of water storage whether flowable composite was used or not, which was in contrast with the results obtained by Papacchini, et al. ${ }^{(14)}$ They reported that the use of flowable composite did not encourage the uptake of silver nitrate at composite/composite interface after thermocycling for 5000 cycles. The difference in flowable composite application could be the reason of such inconsistency.

Score $4(>75 \%-100 \%)$ was the predominant nano-leakage score percentage after $6 \mathrm{~m}$ in all experimental groups, and the Category 3 showed the highest percentage in all experimental groups $(66.67 \%-96.67 \%)$. The hydrophilicity of the "allin-one" adhesive used in this study could be the reason of these findings. G-Premio Bond contains acetone/water as solvent, with the percentage of acetone ranges from $25 \%$ up to $50 \%$ and water is around $24 \%,{ }^{(31)}$ which might make such adhesive extremely hydrophilic. The hydrophilicity of adhesives determined their water sorption and solubility parameters. ${ }^{(33)}$ Although strong air blowing is recommended by the adhesive's manufacturer, yet the recommended short air-drying time $(5 \mathrm{~s})$ might not be enough to optimally removed solvent/ water from the adhesive layer during the air-drying step. Water could defuse within the adhesives, even so they applied over a water-free substrate. ${ }^{(34)}$ In this regard, water containing substrate, as aged resin composite in this study, could greatly encourage the water diffusion through the adhesive, especially when the specimens were stored before interface integrity evaluation. it was expected that the presence of residual water within the adhesive layer could lead to the decrease in its degree of polymerization. ${ }^{(31)}$ In this study, although water sorption of the adhesive was not tested, it could be speculated that its effect could be indirectly determined by the nano-leakage testing. Water sorption of the adhesives could cause the formation of water channels that silver nitrate particles could follow. In the SEM photomicrographs for $24 \mathrm{~h}$
(Figure 1D), the presence of separate islands of silver nitrate deposition within the adhesive layer was observed. In the $6 \mathrm{~m}$ SEM photomicrographs (Figure 1F), the silver nitrate deposition occupied the entire length of the adhesive layer. This could confirm that during storage of repaired resin composite discs, the adhesive was prone to water sorption, due to its hydrophilicity. The increase of water uptake could lead to monomer elusion, ${ }^{(35)}$ leaving nano-defects within the adhesive layer that could be occupied by water. During the immersion of half-discs in silver nitrate solution, the silver nitrate particles could follow the course of these nano-defects, increasing nano-leakage percentage.

Two nano-leakage evaluation methods were used in this study. The "Category" was employed to detect the site of nano-leakage, while the "Score" was used to evaluate the percentage of nano-leakage within each experimental group. Despite the importance of the assessment of the degree of nanoleakage to compare between experimental groups quantitively, the categorization of nano-leakage could be beneficial to trace the sites of nano-leakage, especially in specimens with multiple interfaces. Categorization could also be advantageous to record the cause of nano-leakage, as different nano-leakage causes could lead to different nano-leakage patterns. Category 3 was the predominate Category within all experimental groups. After $24 \mathrm{~h}$ storage period, the high percentage of Category 3 was not accompanied by the high percentage of nano-leakage (Score 4), which was not the condition after the $6 \mathrm{~m}$. After $6 \mathrm{~m}$, Score 4 was increased with the increase in the percentage of Category 3. This could be the reason of the high hydrophilicity of the adhesive used in this study, which was due to its higher solvent content. $^{(32)}$

Although, the two evaluation methods could not be interrelated to each other, interpretations of these two methods could be beneficial to detect qualitatively and quantitively the nano-leakage during immediate storage as well as long-term storage of resin composite specimens. The application of 
hydrophobic flowable resin composite over the hydrophilic adhesive was not beneficial to prevent nano-leakage at composite-composite repair interface. The higher solvent content, ${ }^{(32)}$ and the short evaporation time of the adhesive used in this study appeared to be the cause of increasing nano-leakage between old and new composite layers. Nevertheless, the evaluation of the repair durability using adhesives with different solvent contents and the effect of extended air-drying time should be encountered in the future studies.

\section{CONCLUSIONS}

Under the limitations of this study, the following conclusions could be suggested:

1- The two types of flowable composites were not able to prevent the uptake of silver nitrate at the composite/composite interface either after $24 \mathrm{~h}$ or $6 \mathrm{~m}$.

2- The adhesive tested seemed to be the crucial element in nano-leakage expression at the composite/composite interface.

3- SEM observation revealed that the two evaluation periods showed different reasons of nanoleakage.

4- The two nano-leakage assessment methods, Scores and Categories, seemed to be of importance to assess nano-leakage both qualitatively and quantitively at composite/composite interface.

Clinical significance: The application of flowable resin composite over the universal adhesive used in this study is not necessary, as it did not prevent the nano-leakage at composite-composite interface.

Conflict of interest: The authors declare that they had no conflict of interest regarding the materials used in this study.

\section{REFERENCES}

1. Meereis C, Münchow E, da Rosa W, da Silva AF, Piva E. Polymerization shrinkage stress of resin-based dental materials: A systematic review and meta-analyses of composition strategies. J Mech Behev Biomed Mater 2018; $82: 268-281$

2. Maas MS, Alania Y, Natale L, Rodrigues M, Watts D, Braga $\mathrm{R}$. Trends in restorative composites research: What is in the future? J Bra Oral Res 2017;31:23-36

3. Alqarni D, Nakajima M, Hosaka K, et al. The repair bond strength to resin matrix in cured resin composites after water aging. Dent Mater 2019;38:233-240.

4. Wendler M, Belli R, Panzer R, Skibbe D, Petschelt A, Lohbauer U. Repair bond strength of aged resin composite after different surface and bonding treatments. App Sci 2016;9:1-12

5. Anjum A, Matin K, Uchida R, Tagami J. Influence of aging on direct resin composite repair bond. Inter Chin $\mathrm{j}$ dent 2008;8:53-61.

6. Szczesio-Wlodarczyk A, Sokolowski J, Kleczewska J, Bociong K. Ageing of dental composites based on methacrylate resins-A critical review of the causes and method of assessment. App Sci 2020;12:1-18.

7. Brunton P, Ghazali A, Tarif Z, et al. Repair vs replacement of direct composite restorations: a survey of teaching and operative techniques in Oceania. J Dent 2017;59:62-67.

8. Kanzow P, Wiegand A, Schwendicke F. Cost-effectiveness of repairing versus replacing composite or amalgam restorations. J Dent 2016;54:41-47.

9. Maria A, Charikleia P, Panagiotis L. Attitudes of Greek dentists towards repair of conservative restorations. An online survey. Inter Dent J 2017;67:351-359.

10. Muñoz M, Sezinando A, Luque-Martinez I, et al. Influence of a hydrophobic resin coating on the bonding efficacy of three universal adhesives. J Dent 2014;42:595-602.

11. Flury S, Dulla F, Peutzfeldt A. Repair bond strength of resin composite to restorative materials after short- and long-term storage. Dent Mater 2019;35:1205-1213.

12. Costa T, Serrano A, Atman A, Loguercio A, Reis A. Durability of composite repair using different surface treatments. J Dent 2012;40:513-521.

13. Costa T, Ferreira S, Klein-Júnior C, Loguercio A, Reis A. Durability of surface treatments and intermediate agents 
used for repair of a polished composite. Oper Dent 2010;35:231-237.

14. Papacchini F, Toledano M, Monticelli F, et al. Hydrolytic stability of composite repair bond. Eur J Oral Sci 2007; 115:417-424.

15. Altinci P, Mutluay M, Tezvergil-Mutluay A. Repair bond strength of nanohybrid composite resins with a universal adhesive. J Acta Biomater Odontol Scand 2018;4(1):10-19.

16. Eren D, Doğan C, Bektaş Ö. Effect of Different Surface Treatments and Roughness on the Repair Bond Strength of Aged Nanohybrid Composite. J Photobiomod, Photomed, and Laser Surgery 2019;37:473-482.

17. Cuevas-Suárez C, Nakanishi L, Isolan C, Ribeiro J, Moreira A, Piva E. Repair bond strength of bulk-fill resin composite: Effect of different adhesive protocols. Dent Mater 2020;39:236-241.

18. Papacchini F, Magni E, Radovic I, et al. Effect of intermediate agents and pre-heating of repairing resin on compositerepair bonds. Oper Dent 2007;32:363-371.

19. Al-Ahdal K, Silikas N, Watts D. Rheological properties of resin composites according to variations in composition and temperature. Dent Mater 2014;30:517-524.

20. GC Australasia Dental Pty Ltd. Brochure of G-aenial Flo X. http://www.gcaustralasia.com/. http://www.gcaustralasia.com/

21. Ahmed M, Yao C, van Landuyt K, Peumans M, van Meerbeek B. Extra Bonding Layer Compensates Universal Adhesive's Thin Film Thickness. J Adhes Dent 2020; 22:483-501.

22. Kwon Y, Ferracane J, Lee I. Effect of layering methods, composite type, and flowable liner on the polymerization shrinkage stress of light cured composites. Dent mater 2012;28(7):801-809.

23. Pashley E, Agee K, Pashley D, Tay F. Effects of one versus two applications of an unfilled, all-in-one adhesive on dentine bonding. J Dent 2002;30:83-90.
24. Saboia V, Nato F, Mazzoni A, et al. Adhesion of a Two-step Etch-and-Rinse Adhesive on Collagen-depleted Dentin. J Adhes Dent 2008;10:419-422.

25. Hickel R, Brüshaver K, Ilie N. Repair of restorations - Criteria for decision making and clinical recommendations. Dent Mater 2013;29:28-50.

26. García A, Lozano M, Vila J, Escribano A, Galve P. Composite resins: A review of the materials and clinical indications. J Med Oral Patol Oral Cir Bucal 2006;11:E215-E220.

27. Yang H, Guo J, Guo J, et al. Nanoleakage evaluation at adhesive-dentin interfaces by different observation methods. Dent Mater 2015;34:654-662.

28. Fawzy A, El-Askary F, Amer M. Effect of surface treatments on the tensile bond strength of repaired water-aged anterior restorative micro-fine hybrid resin composite. J Dent 2008;36:969-976.

29. Ferracane JL. Hygroscopic and hydrolytic effects in dental polymer networks. Dent Mater 2006;22:211-222.

30. Kanzow P, Wiegand A, Göstemeyer G, Schwendicke F. Understanding the management and teaching of dental restoration repair: Systematic review and meta-analysis of surveys. J Dent 2018;69:1-21.

31. Tay F, Pashley D, Yoshiyama M. Two modes of nanoleakage expression in single-step adhesives. J Dent Res 2002;81:472-476.

32. Ahmed M, de Munck J, van Landuyt K, Peumans M, Yoshihara $\mathrm{K}$, van Meerbeek B. Do universal adhesives benefit from an extra bonding layer? J Adhes Dent. 2019;21:117-132.

33. Malacarne J, Carvalho R, de Goes M, et al. Water sorption/solubility of dental adhesive resins. Dent Mater 2006;22:973-980.

34. Malacarne J, Silva S, Wang L, et al. Permeability of Dental Adhesives-A SEM Assessment. Eur J Dent. 2010;4:429-439.

35. Sideridou I, Tserki V, Papanastasiou G. Study of water sorption, solubility and modulus of elasticity of light-cured dimethacrylate-based dental resins. J Biomater 2003;24:655-665. 